\title{
Regeneration of Potassium Poisoned Catalysts for the Selective Catalytic Reduction of $\mathrm{NO}$ with $\mathrm{NH}_{3}$
}

\author{
Shaojun Liu ${ }^{1,2,3}$, Peidong $\mathrm{Ji}^{1}$, Dong Ye ${ }^{1}$, Ruiyang $\mathrm{Qu}^{1}$, Chenghang Zheng ${ }^{1}$, Xiang Gao ${ }^{{ }^{*}}$ \\ ${ }^{1}$ State Key Laboratory of Clean Energy Utilization, Zhejiang University, Hangzhou 310027, China \\ ${ }^{2}$ School of Energy and Power, Jiangsu University of Science and Technology, Zhenjiang 212003, China \\ ${ }^{3}$ Key Laboratory of Low-grade Energy Utilization Technologies and Systems (Chongqing University), Ministry of \\ Education of China, Chongqing University, Chongqing 400044, China
}

\begin{abstract}
In this study, we investigated the effect of potassium on the activity and regeneration of potassium-poisoned SCR catalysts. With the addition of potassium species, the NO conversion rate of the catalysts continuously decreased. After washing the poisoned catalysts with an $\mathrm{H}_{2} \mathrm{SO}_{4}$ solution or doping them with $\mathrm{CeO}_{2}$, the activity of the catalysts was improved to different extents. Acid washing almost completely removed the surface potassium species, freeing acidic sites to adsorb $\mathrm{NH}_{3}$, but it also potentially removed some of the active components, such as vanadia. $\mathrm{CeO}_{2}$ doping, on the other hand, added active components. Combining these two methods, the poisoned catalysts were washed with an $\mathrm{H}_{2} \mathrm{SO}_{4}$ solution and then doped with $5 \mathrm{wt} . \% \mathrm{CeO}_{2}$. It was found that the level of activity could be restored to that of a fresh catalyst, and a conversion rate of over $90 \%$ was observed for $\mathrm{NO}$ between $300^{\circ} \mathrm{C}$ and $450^{\circ} \mathrm{C}$, as the added $\mathrm{CeO}_{2}$ compensated for the active components lost during SCR reactions. Consequently, the above hybrid method shows high potential for regenerating commercial SCR catalysts.
\end{abstract}

Keywords: Selective catalytic reduction; Potassium; Deactivation; Regeneration; Ceria.

\section{INTRODUCTION}

The selective catalytic reduction (SCR) of $\mathrm{NO}_{\mathrm{x}}$ with $\mathrm{NH}_{3}$ has been regarded as an effective method to control $\mathrm{NO}_{\mathrm{x}}$ emissions from stationary and mobile sources (Busca et al., 1998). The commercial SCR catalysts consist of $\mathrm{TiO}_{2}$ as support and $\mathrm{V}_{2} \mathrm{O}_{5}-\mathrm{WO}_{3}$ or $\mathrm{V}_{2} \mathrm{O}_{5}-\mathrm{MoO}_{3}$ as active components. They are shaped into honeycomb matrix because of the advantages such as low pressure drop, high geometric surface area, and resistance to deposition of dust (Lei et al., 2009).

The (co-)firing of biomass is a significant way to reduce the net $\mathrm{CO}_{2}$ emissions. However, high levels of alkali and alkaline earth metals, especially potassium, are present in the fly ash of the biomass fired systems. And potassium has been demonstrated to do harm to the SCR catalysts (Kamata et al., 1999; Moradi et al., 2003; Zheng et al., 2004, 2005; Due-Hansen et al., 2007; Castellino et al., 2009; Klimczak et al., 2010). Doping with alkali and alkaline earth metals results in a strong catalyst deactivation and

\footnotetext{
* Corresponding author.

Tel.: 1-350-571-1887; Fax: 1-350-571-1887

E-mail address: xgao1@zju.edu.cn
}

the poisoning effect of alkali and alkaline earth metals is related to their basicity. The order is listed as $\mathrm{K}>\mathrm{Na}>\mathrm{Ca}>$ $\mathrm{Mg}$ (Klimczak et al., 2010). It is concluded that potassium preferentially coordinates to the Brønsted acid sites, which are responsible for the ammonia adsorption, thus decreasing their number and strength of the Brønsted acid sites. As a result, catalyst activity would be adversely affected. A deactivation of about $1 \%$ per day was found over monolith catalysts, which were exposed in a high-dust flue gas produced from straw-fired grate boiler (Zheng et al., 2005).

The cost of the catalysts is a major part of the total expense in an SCR system. Hence, it is important and necessary to regenerate the catalysts (Du et al., 2018; Wang et al., 2018a, b). Regeneration by washing with water followed by sulfation was not an optimal regeneration method due to the insufficient removal of the poison (Zheng et al., 2004). Washing with sulfuric acid can remove potassium accumulated on the surface and recover the catalytic activity (Khodayari and Odenbrand, 2001a, b; Zheng et al., 2004). However, active components such as vanadium and tungsten can also be removed through washing with sulfuric acid. So, it is necessary to compensate the loss of the active components. Recently, ceria-based catalysts have been investigated for SCR reactions because of the high oxygen storage capacity and excellent redox properties of $\mathrm{CeO}_{2}$ (Li et al., 2012; Hu et al., 2017; Huang 
et al., 2017; Jiang et al., 2017; Li et al., 2017; Yao et al., 2017; Chen et al., 2018; Jiang et al., 2018). We could also add ceria on the catalyst to compensate the loss of the active components.

In this work, potassium ions were doped on the commercial $\mathrm{V}_{2} \mathrm{O}_{5}-\mathrm{WO}_{3} / \mathrm{TiO}_{2}$ catalysts to simulate the poison effect. Then, a study of the regeneration of $\mathrm{K}$-poisoned catalysts was presented. Specifically, loading different amount of ceria on the deactivated catalysts with or without sulfuric acid and deionized water washing have been investigated to show the commercial potential of ceriainvolved regeneration method.

\section{METHODS}

\section{Catalyst Preparation}

The commercial honeycomb-type catalysts used in this investigation were obtained from RAGA Technology Co., Ltd. The catalysts contained about $1 \% \mathrm{~V}_{2} \mathrm{O}_{5}$ and $5 \% \mathrm{WO}_{3}$ as active phase doped on a $\mathrm{TiO}_{2}$ support. The catalyst had a wall thickness of $1 \mathrm{~mm}$ and a channel pitch of $6 \mathrm{~mm}$. The catalysts were cut into $25 \mathrm{~mm} \times 20 \mathrm{~mm} \times 20 \mathrm{~mm}$ blocks for poisoning of potassium and regeneration method tests.

\section{Deactivation of Catalysts}

The catalysts doped with potassium were prepared by wet-impregnation method with aqueous solutions of $\mathrm{KNO}_{3}$. The prepared monolithic catalysts were immersed into $25 \mathrm{~mL}$ aqueous solutions with different concentration of $\mathrm{KNO}_{3}$. Then the samples were first dried at $110^{\circ} \mathrm{C}$ overnight and then calcined at $500^{\circ} \mathrm{C}$ for $5 \mathrm{~h}$ in a muffle furnace to form potassium oxide.

\section{Regeneration of Deactivated Catalysts}

Several blocks of deactivated catalysts $(25 \mathrm{~mm}$ long monolithic segment) were washed in $1000 \mathrm{~mL} 0.5 \mathrm{M}$ sulfuric acid (SA) solution for $120 \mathrm{~min}$ and then washed in $1000 \mathrm{~mL}$ deionized water for $15 \mathrm{~min}$. In some cases, different concentrations of sulfuric acid $(0.05 \mathrm{M}, 0.1 \mathrm{M}$, $0.3 \mathrm{M}, 0.5 \mathrm{M}, 0.7 \mathrm{M}$ ) were used to optimize the washing process. The washing process was under continuous stirring. The temperature of the washing solution was kept at $50^{\circ} \mathrm{C}$. After washing, different contents of $\mathrm{CeO}_{2}$ were loaded on the catalysts using the same method as potassium doping. Another regeneration method was that $\mathrm{CeO}_{2}$ was added on the deactivated catalysts without washing process. The catalysts were donated as $x \mathrm{~K}-y \mathrm{SA}-z \mathrm{CeO}_{2} . x$ represents the loading of potassium element (wt.\%), $y$ represents the concentration of SA (sulfuric acid) used for catalysts washing (M) and $z$ represents the loading of $\mathrm{CeO}_{2}$ (wt.\%) on the catalysts.

\section{Activity Tests}

The activity tests for the reduction of $\mathrm{NO}$ by $\mathrm{NH}_{3}$ were carried out in a fixed bed quartz micro-reactor (inner diameter: $4 \mathrm{~mm}$ ) with $0.2 \mathrm{~g}$ catalyst power of $250-380 \mu \mathrm{m}$ in diameter. The feed gas mixture contained $1000 \mathrm{ppm}$ $\mathrm{NO}, 1000 \mathrm{ppm} \mathrm{NH}_{3}, 5$ vol. $\% \mathrm{O}_{2}$ and $\mathrm{N}_{2}$ as the balance gas. The total flow rate of the feed gas was $1000 \mathrm{~mL} \mathrm{~min}^{-1}$ and the GHSV was $183,000 \mathrm{~h}^{-1}$. The catalytic reaction was carried out with temperature ranging from $150^{\circ} \mathrm{C}$ to $450^{\circ} \mathrm{C}$. The concentrations of $\mathrm{NO}$ and $\mathrm{N}_{2} \mathrm{O}$ before and after reaction were measured by an FTIR gas analyzer, the Gasmet DX4000. The NO conversion is defined as

NO Conversion $(\%)=\frac{\mathrm{NO}_{\text {in }}-\mathrm{NO}_{\text {out }}}{\mathrm{NO}_{\text {in }}} \times 100$

where $\mathrm{NO}_{\text {in }}$ and $\mathrm{NO}_{\text {out }}$ stand for the $\mathrm{NO}$ concentration at the inlet and outlet, respectively.

\section{Catalyst Characterization}

The specific surface area and the textural properties (i.e., pore volume and average pore diameter) were measured by $\mathrm{N}_{2}$ adsorption and desorption experiments at liquid nitrogen temperature $\left(-196^{\circ} \mathrm{C}\right)$ with Autosorb-1-C instrument (Quantachrome Instrument Corp.). The specific surface area was calculated by the Brunauer-Emmett-Teller (BET) method while the average pore diameter was calculated from the surface area and BET pore volume.

The X-ray diffraction (XRD) patterns were collected using a Panalytical X'pert Pro diffractometer equipped with $\mathrm{Cu} \mathrm{Ka}$ radiation. The X-ray tube was operated at $40 \mathrm{kV}$ and $40 \mathrm{~mA}$.

The chemical composition of catalyst samples was analyzed by inductively coupled plasma-mass spectroscopy (ICP-MS; 7500a, Agilent) after the catalysts dissolved completely.

$\mathrm{NH}_{3}$-TPD tests were carried out on an AutoChem 2920 instrument provided by Micromeritics Corporation. $\mathrm{NH}_{3}$ signal was detected using a Hiden QIC20 mass spectrum instrument. $0.2 \mathrm{~g}$ catalyst powder was pretreated in $\mathrm{He}$ at $500^{\circ} \mathrm{C}$ for $30 \mathrm{~min}$. After that, the sample was cooled to $100^{\circ} \mathrm{C}$ and exposed to a gas mixture of $5 \% \mathrm{NH}_{3}$ in $\mathrm{He}$ for $30 \mathrm{~min}$. Then the sample was flushed with pure He until signal was stabilized. The sample was then heated up to $700^{\circ} \mathrm{C}$ at a rate of $10^{\circ} \mathrm{C} \mathrm{min}^{-1}$.

$\mathrm{H}_{2}$-TPR was also carried out in a quartz-tube reactor. $0.10 \mathrm{~g}$ catalyst powder was pre-treated at $200^{\circ} \mathrm{C}$ in $\mathrm{N}_{2}$ for $30 \mathrm{~min}$. After that, the sample was cooled to room temperature and then heated to $700^{\circ} \mathrm{C}$ at a rate of $10^{\circ} \mathrm{C} \mathrm{min}{ }^{-1}$ in a gas mixture of $5 \mathrm{vol} . \% \mathrm{H}_{2}$ and Ar. The consumption of $\mathrm{H}_{2}$ was detected by a thermal conductivity detector (TCD).

\section{RESULTS AND DISCUSSION}

\section{Activity and Selectivity \\ Effect of Potassium Poisoning}

Fig. 1 shows the activity of the fresh and potassiumloaded catalysts. For the fresh catalyst, the NO conversion increased as the temperature increased, which almost reached $100 \%$ at $350^{\circ} \mathrm{C}$. Given that potassium was introduced, the NO conversion decreased. With the increase in the doping amount of potassium, catalyst activity continuously decreased. When the potassium loading amount reached $1 \%$, the NO conversion of the catalyst was always below $30 \%$. This is consistent with the result of Chen et al. (2011). 


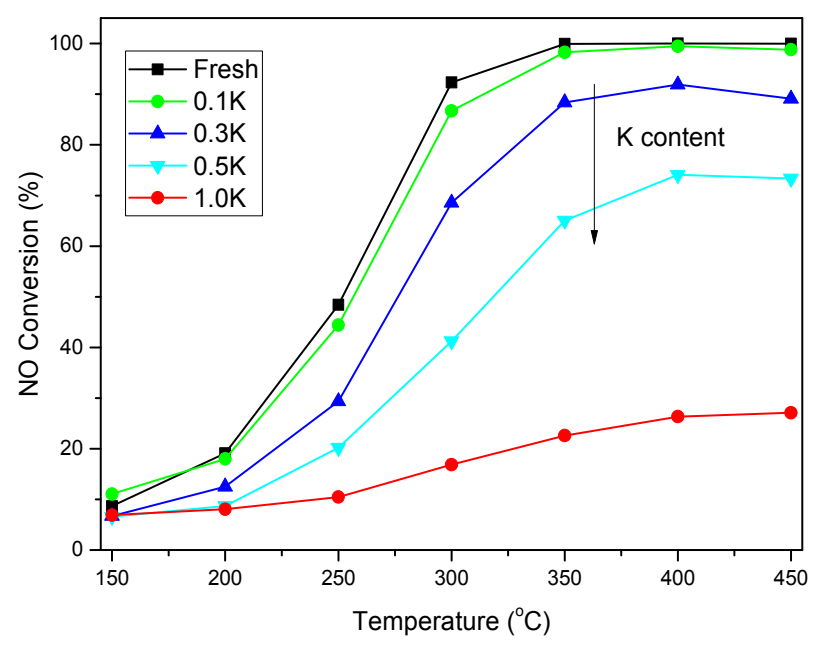

Fig. 1. NO conversion of the catalysts poisoned with different $\mathrm{K}$ loading amounts.

\section{Effect of Acid Washing}

To regenerate the poisoned catalyst, the first step is to remove the accumulated K. Sulfuric acid was used as detergent combined with fresh water rinsing after the process. Different concentrations of sulfuric acid solutions were chosen and effect on NO conversion is depicted in Fig. 2. It is clear that with concentrated acid, poisoned catalyst is easily recovered, approaching its initial state. However, this effect was gradually weakened when the concentration increased from $0.05 \mathrm{M}$ to $0.5 \mathrm{M}$. Specially, no obvious difference was observed for the catalysts treated with $0.5 \mathrm{M}$ and $0.7 \mathrm{M} \mathrm{H}_{2} \mathrm{SO}_{4}$. As a result, $0.5 \mathrm{M} \mathrm{H}_{2} \mathrm{SO}_{4}$ was used in later section for acid washing. Moreover, the washing process also contributed to loss of active components, such as $\mathrm{V}$ and $\mathrm{W}$. The negative effect of acid washing is shown in Fig. S1 in supporting information. The effect of washing time was also evaluated. It is evident that using diluted acid and short time could remove most of $\mathrm{K}$ and reduce the loss of V. However, as shown in Fig. 2, the diluted acid washing couldn't totally recover the activity of the catalyst. On the other hand, after $2 \mathrm{~h}$ washing with 0.5 $\mathrm{M} \mathrm{H}_{2} \mathrm{SO}_{4}, 40 \% \mathrm{~V}$ of the catalyst was dissolved into the solution, resulting in the reduction of the activity, especially in lower temperatures $\left(<350^{\circ} \mathrm{C}\right)$. For this reason, it is necessary to load active components to compensate the loss.

\section{Effect of $\mathrm{CeO}_{2}$ Loading}

The NO conversion of the K-poisoned and regenerated catalysts is presented in Fig. 3. The direct loading of $10 \%$ $\mathrm{CeO}_{2}$ to the deactivated catalyst could improve the activity, which was, however, much lower than that of the fresh catalyst. This is because potassium still remained on the catalyst and exerted a negative effect on the catalyst. Thus, removing potassium species constituted the first step to recover the activity of the deactivated catalyst. After washing with $\mathrm{H}_{2} \mathrm{SO}_{4}$ solution, an obvious enhancement in the high-temperature activity could be obtained, while the activity below $300^{\circ} \mathrm{C}$ remained almost unchanged. It should be noted that the activity of the regenerated catalyst washed

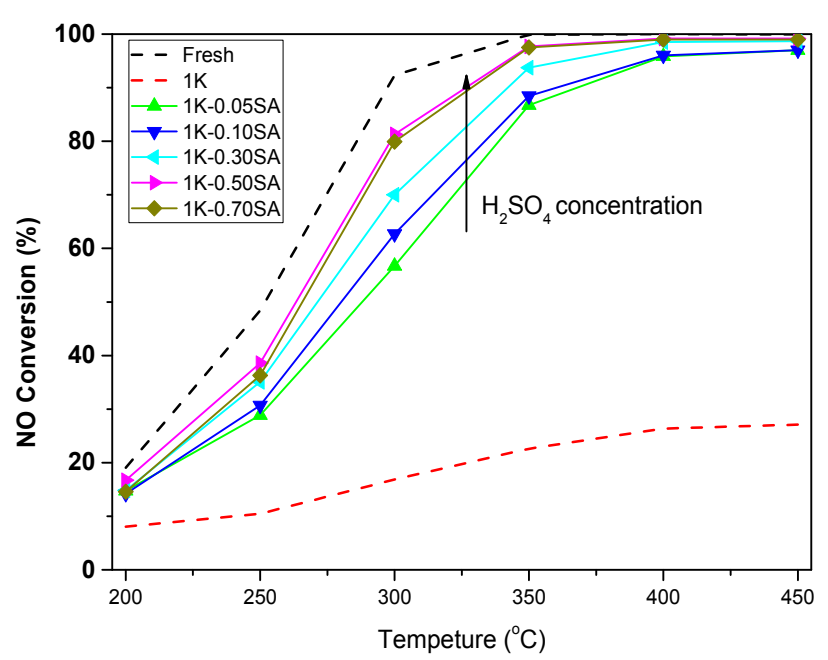

Fig. 2. NO conversion of the catalysts regenerated with different concentrations of $\mathrm{H}_{2} \mathrm{SO}_{4}$ solution.

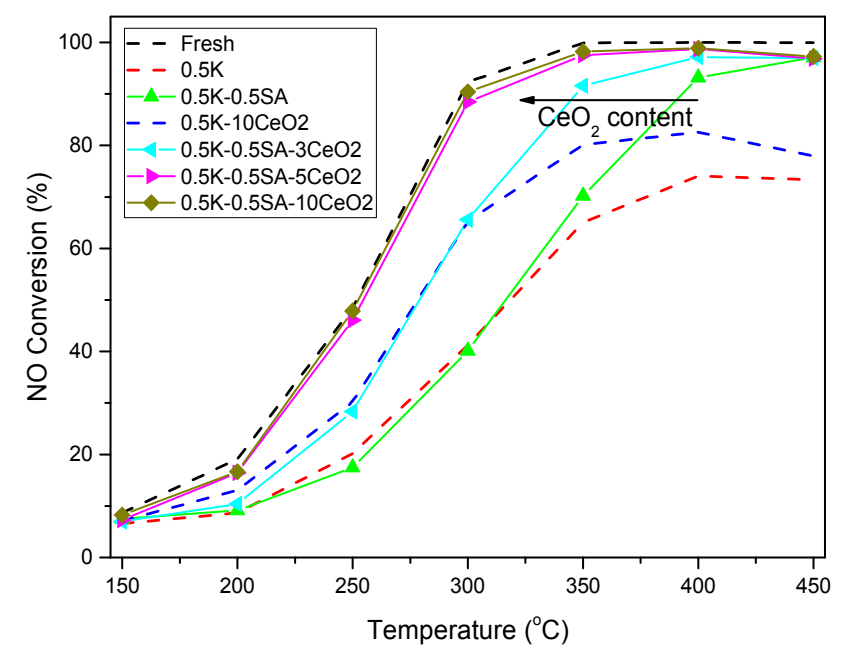

Fig. 3. NO conversion of the catalysts regenerated with different cerium loading amounts.

with $\mathrm{H}_{2} \mathrm{SO}_{4}$ solution was still lower than that of the fresh one. That might be due to the loss of active components during the $\mathrm{H}_{2} \mathrm{SO}_{4}$ solution washing process. Therefore, various amounts of $\mathrm{CeO}_{2}$ were added to the deactivated catalysts after treatment by $0.5 \mathrm{M} \mathrm{H}_{2} \mathrm{SO}_{4}$ and deionized water. The NO conversion of $0.5 \mathrm{~K}-0.5 \mathrm{SA}-3 \mathrm{CeO}_{2}$ catalyst is almost the same as that of the $0.5 \mathrm{~K}-10 \mathrm{CeO}_{2}$ catalysts below $300^{\circ} \mathrm{C}$. With temperature increasing, $0.5 \mathrm{~K}-0.5 \mathrm{SA}-$ $3 \mathrm{CeO}_{2}$ catalyst exhibited a better activity than that of $0.5 \mathrm{~K}-10 \mathrm{CeO}_{2}$ catalyst. When the loading amount of $\mathrm{CeO}_{2}$ exceeded $5 \mathrm{wt} . \%$, the activity of the regenerated catalysts almost restored to the level of the fresh one. Thus, it seems that washing with $0.5 \mathrm{M}$ sulfuric acid solution and deionized water and then doping with $5 \mathrm{wt} . \% \mathrm{CeO}_{2}$ is a good method to regenerate the $\mathrm{K}$-poisoned catalysts.

In order to investigate the adaptability of this regeneration method, catalyst with a higher potassium loading amount were chosen and tested. As illustrated in Fig. 4, it can be concluded that the amount of potassium had no obvious 


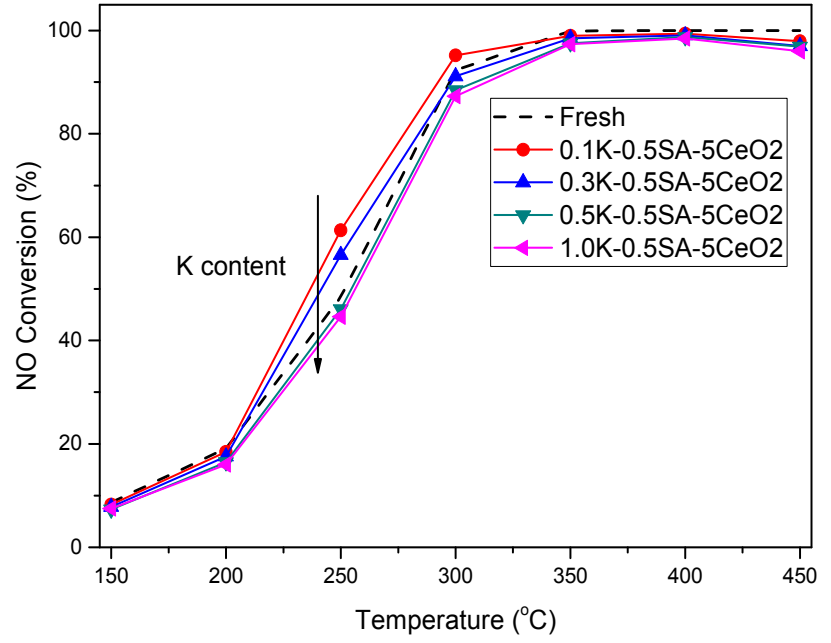

Fig. 4. Effect of $\mathrm{K}$ content on the catalysts regenerated by washing and $\mathrm{CeO}_{2}$ modification.

effect on the activity of the regenerated catalysts in the investigated range and the activity of the regenerated catalysts is almost the same as that of the fresh one. This indicated that $0.5 \mathrm{M} \mathrm{H}_{2} \mathrm{SO}_{4}$ and deionized water treatment could remove potassium species that interacted with the active sites, and 5 wt. $\% \mathrm{CeO}_{2}$ additives could supply extra active sites to some extent.

\section{Selectivity of Regenerated Catalysts}

In addition to $\mathrm{NO}$ conversion, $\mathrm{N}_{2} \mathrm{O}$ formation is also an important parameter to evaluate catalyst performance. Fig. 5 displays $\mathrm{N}_{2} \mathrm{O}$ formation in the SCR reactions. For the fresh and regenerated catalysts, the $\mathrm{N}_{2} \mathrm{O}$ concentration were fairly low $(<5 \mathrm{ppm})$ below $350^{\circ} \mathrm{C}$. As the temperature increased, $\mathrm{N}_{2} \mathrm{O}$ concentration of the fresh catalyst rapidly increased up to $47 \mathrm{ppm}$ at $450^{\circ} \mathrm{C}$, while the $\mathrm{N}_{2} \mathrm{O}$ formation of the regenerated catalysts stayed below $17 \mathrm{ppm}$, suggesting a better selectivity than the fresh one. This phenomenon could be explained by the reduction of $\mathrm{V}$ and the addition of $\mathrm{Ce}$, confirmed by Fig. $\mathrm{S} 1$ and Table 1 . Since $\mathrm{V}_{2} \mathrm{O}_{5}$ has a strong ability to oxidize $\mathrm{NH}_{3}$ into $\mathrm{N}_{2} \mathrm{O}$ at higher temperatures (Chen et al., 2009), decrease of $\mathrm{V}_{2} \mathrm{O}_{5}$ could weaken this side reaction and improve the selectivity of SCR reaction.

\section{Characterization of the Catalysts}

\section{Chemical Composition and BET Analysis}

Table 1 shows the ICP-MS and BET results of the fresh and regenerated catalysts. It seems that no obvious variations could be observed in these catalysts, partly ruling out the possibility that physical properties mainly determined the activity of the catalysts. Instead, the variations in the chemical properties including acidity and redox constituted the main reason for enhanced activity of the catalysts after regeneration.

The ICP-MS results showed that the washing process could drastically remove potassium species over catalyst surface. At the same time, vanadia, as the active component, was also removed by a third with the content of tungsten remaining almost unchanged after the washing process.

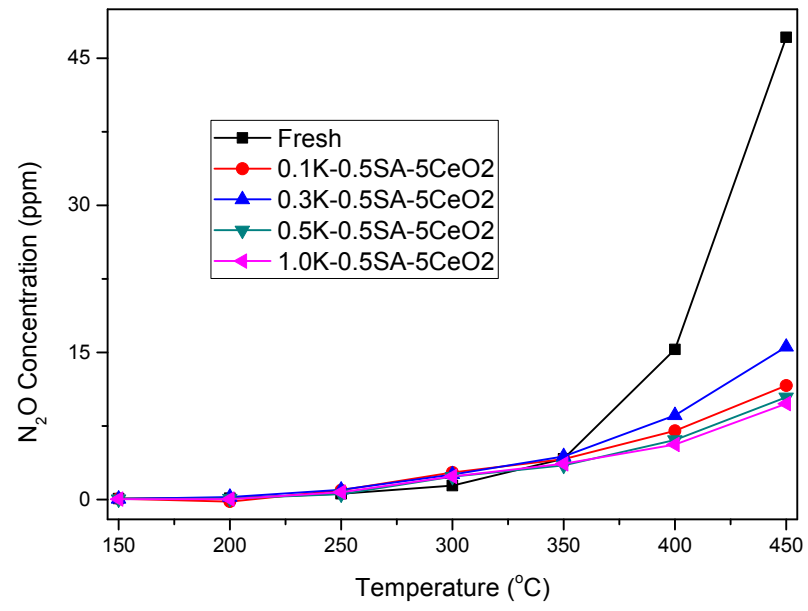

Fig. 5. $\mathrm{N}_{2} \mathrm{O}$ formation of the catalysts regenerated by washing and $\mathrm{CeO}_{2}$ modification.

Additionally, the measured Ce content was lower than the calculated value. This meant that there was loss of $\mathrm{Ce}$ during impregnation process.

\section{XRD Analysis}

XRD patterns of the series catalysts are shown in Fig. 6 . All the catalysts presented anatase $\mathrm{TiO}_{2}$ phase with the absence of $\mathrm{V}_{2} \mathrm{O}_{5}$ and $\mathrm{WO}_{3}$ crystallites, indicating that $\mathrm{V}_{2} \mathrm{O}_{5}$ and $\mathrm{WO}_{3}$ were amorphous in structure on the $\mathrm{TiO}_{2}$ support (Lisi et al., 2004; Kustov et al., 2005; Zhang et al., 2009). Given the addition of $3 \% \mathrm{CeO}_{2}$, no cubic $\mathrm{CeO}_{2}$ phase could be detect. This result indicated that ceria were highly dispersed and existed as an amorphous state. Further increasing the $\mathrm{CeO}_{2}$ loading amount to $5 \%$ or more, cubic $\mathrm{CeO}_{2}$ phase began to be observed, suggesting that $\mathrm{CeO}_{2}$ loading was beyond the theoretical monolayer coverage on the $\mathrm{TiO}_{2}$ support.

\section{$\mathrm{NH}_{3}-\mathrm{TPD}$}

According to previous studies, acidity plays an important role in the SCR reactions, since the first step is the adsorption of $\mathrm{NH}_{3}$ on the surface acidic sites of catalyst (Busca et al., 1998; Forzatti, 2001; Ye et al., 2018). $\mathrm{NH}_{3}-$ TPD tests were carried out to investigate surface acidity of the series samples, and the results of which are illustrated in Fig. 7. The $0.5 \mathrm{~K}$ and $0.5 \mathrm{~K}-10 \mathrm{CeO}_{2}$ catalysts had several $\mathrm{NH}_{3}$ desorption peaks in the temperature region of 100 $350^{\circ} \mathrm{C}$, while the other catalysts possessed broad desorption peaks between $100^{\circ} \mathrm{C}$ and $450^{\circ} \mathrm{C}$. The peaks near $170^{\circ} \mathrm{C}$ (Peak I) could be assigned to the desorption of physisorbed $\mathrm{NH}_{3}$, and the peaks around $270^{\circ} \mathrm{C}$ (Peak II) were attributed to $\mathrm{NH}_{3}$ on weakly acidic sites, while the peaks centering at $610^{\circ} \mathrm{C}$ (Peak III) linked to the strongly acidic sites (Guan et al., 2011; Li et al., 2012; Li et al., 2017; Yao et al., 2017). The quantity analysis of $\mathrm{NH}_{3}$-TPD is summarized in Table 2 . For the $0.5 \mathrm{~K}$ and $0.5 \mathrm{~K}-10 \mathrm{CeO}_{2}$ catalysts, the presence of potassium caused the reduction of Peak II, which correlated with acidic sites, responsible for SCR activity (Forzatti, 2001). After washing process, abundant acidic sites were present, and $\mathrm{NH}_{3}$ could be adsorbed on 
Table 1. Chemical composition, BET surface area, total pore volume, and average pore diameter of different samples.

\begin{tabular}{llllllll}
\hline \multirow{2}{*}{ Sample } & \multicolumn{4}{c}{ Amount (wt \%) } & $\begin{array}{l}\text { Surface area } \\
\left(\mathrm{m}^{2} \mathrm{~g}^{-1}\right)\end{array}$ & $\begin{array}{l}\text { Total pore volume } \\
\left(\mathrm{cm}^{3} \mathrm{~g}^{-1}\right)\end{array}$ & $\begin{array}{l}\text { Average pore } \\
\text { diameter }(\mathrm{nm})\end{array}$ \\
\cline { 2 - 5 } & $\mathrm{V}$ & $\mathrm{W}$ & $\mathrm{K}$ & $\mathrm{Ce}^{\mathrm{a}}$ & 63.3 & 0.312 & 19.71 \\
$0.5 \mathrm{~K}$ & 0.67 & 3.72 & 0.03 & 0.00 & -3.3 & 0.309 & 18.55 \\
$0.5 \mathrm{~K}-0.5 \mathrm{SA}$ & 0.73 & 4.16 & 0.34 & - & 66.7 & 0.346 & 22.06 \\
$0.5 \mathrm{~K}-10 \mathrm{CeO}_{2}$ & 0.44 & 3.90 & 0.05 & - & 62.7 & 0.301 & 18.48 \\
$0.5 \mathrm{~K}-0.5 \mathrm{SA}-3 \mathrm{CeO}_{2}$ & 0.61 & 3.35 & 0.25 & 9.54 & 65.1 & 0.353 & 20.91 \\
$0.5 \mathrm{~K}-0.5 \mathrm{SA}-5 \mathrm{CeO}_{2}$ & 0.44 & 3.90 & 0.04 & 1.37 & 67.5 & 0.330 & 20.21 \\
$0.5 \mathrm{~K}-0.5 \mathrm{SA}-10 \mathrm{CeO}_{2}$ & 0.39 & 3.76 & 0.04 & 2.36 & 65.4 & 0.274 & 18.09 \\
\hline
\end{tabular}

${ }^{\mathrm{a}} \mathrm{Amount}$ of $\mathrm{Ce}$ is from EDS analysis.

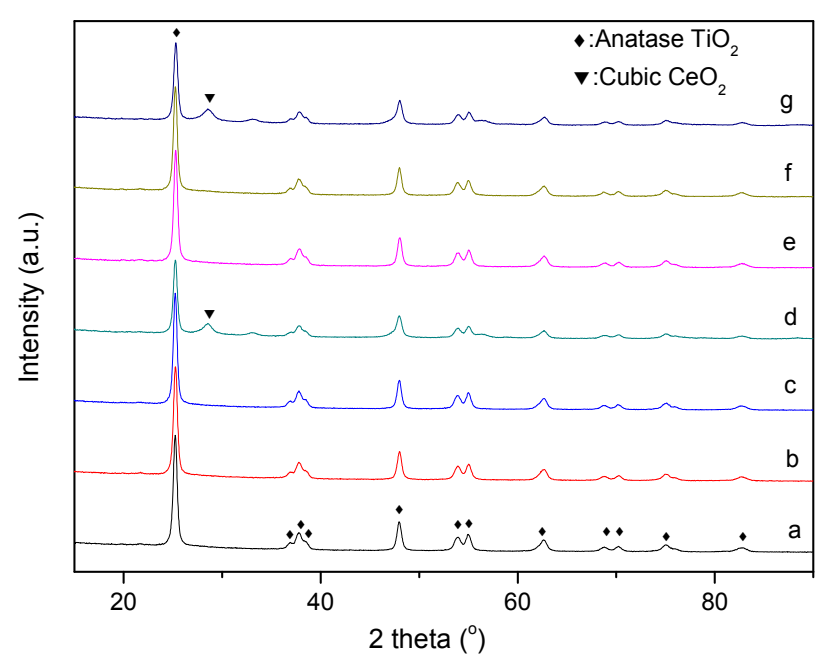

Fig. 6. XRD patterns of the (a) fresh; (b) $0.5 \mathrm{~K}$; (c) $0.5 \mathrm{~K}$ $0.5 \mathrm{SA}$; (d) $0.5 \mathrm{~K}-10 \mathrm{CeO}_{2}$; (e) $0.5 \mathrm{~K}-0.5 \mathrm{SA}-3 \mathrm{CeO}_{2}$; (f) $0.5 \mathrm{~K}-$ $0.5 \mathrm{SA}-5 \mathrm{CeO}_{2} ;(\mathrm{g}) 0.5 \mathrm{~K}-0.5 \mathrm{SA}-10 \mathrm{CeO}_{2}$.

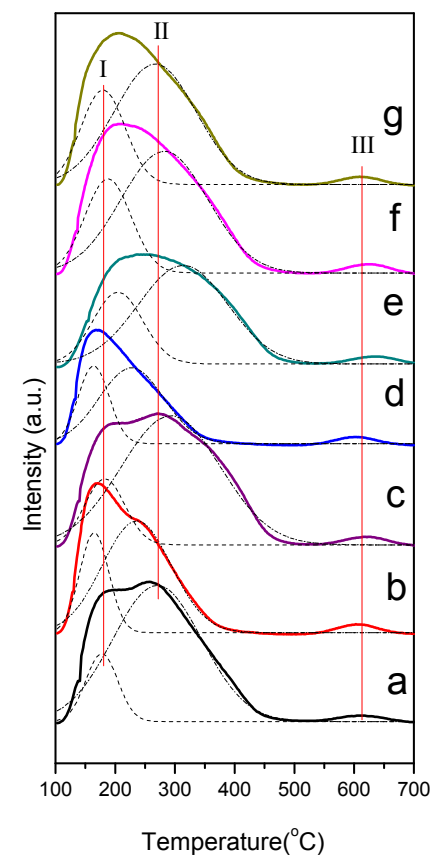

Fig. 7. $\mathrm{NH}_{3}-\mathrm{TPD}$ curves of the (a) fresh; (b) $0.5 \mathrm{~K}$; (c) $0.5 \mathrm{~K}-0.5 \mathrm{SA}$; (d) $0.5 \mathrm{~K}-10 \mathrm{CeO}_{2}$; (e) $0.5 \mathrm{~K}-0.5 \mathrm{SA}-3 \mathrm{CeO}_{2}$; (f) $0.5 \mathrm{~K}-0.5 \mathrm{SA}-5 \mathrm{CeO}_{2} ;(\mathrm{g}) 0.5 \mathrm{~K}-0.5 \mathrm{SA}-10 \mathrm{CeO}_{2}$. the catalyst surface, reacting with NO. Besides, doping $\mathrm{CeO}_{2}$ could also in part enhance the acidity of the catalysts, which made $0.5 \mathrm{~K}-0.5 \mathrm{SA}-5 \mathrm{CeO}_{2}$ catalyst had the same activity with the fresh one (Shi et al., 2017). That is consistent with SCR activity results in Fig. 3. Note that after washing and $\mathrm{CeO}_{2}$ modification, Peak I increased almost up to two times while Peak II reached about $80 \%$ of that of the fresh catalyst. It may be related to promoted SCR activity at low temperatures and inhibited $\mathrm{NH}_{3}$ oxidation at high temperatures.

\section{$H_{2}-T P R$}

The redox properties of the catalysts play an important role in the catalytic cycle of the SCR reactions (Topsoe, 1994; Topsoe et al., 1995; Putluru et al., 2009; Wang et al., 2018). The $\mathrm{H}_{2}$-TPR profiles and quantity analysis are shown in Fig. 8 and Table 2, respectively. The fresh catalyst showed a reduction peak located at $500^{\circ} \mathrm{C}$, while the $0.5 \mathrm{~K}$ sample presented a peak at $523^{\circ} \mathrm{C}$. These peaks could be explained by the reduction of $\mathrm{V}^{5+}$ to $\mathrm{V}^{3+}$ (Tang et al., 2010; Chen et al., 2011; Guan et al., 2011). And it should be noted that the reduction peak shifted to higher temperatures after doping potassium, which is consistent with the results of Chen et al. (2011), showing that potassium doping exerted a negative effect on the catalyst redox properties. After $\mathrm{H}_{2} \mathrm{SO}_{4}$ washing process, a reduction peak at $485^{\circ} \mathrm{C}$ came out. This meant that washing with sulfuric acid solution and deionized water could remove potassium species and recover the redox ability of the catalysts. The reduction peaks shifted to higher temperature with the increasing loading amount of $\mathrm{CeO}_{2}$. Moreover, the adding of $\mathrm{CeO}_{2}$ slightly increased the consumption of $\mathrm{H}_{2}$, compared to $0.5 \mathrm{~K}-0.5 \mathrm{SA}$. This indicated that loading more Ce had a negative effect on the catalyst reducibility. Besides, XPS results shown in Fig. S2 confirmed that no obvious change in chemical state of $\mathrm{V}, \mathrm{W}$ and $\mathrm{Ti}$ after acid washing or $\mathrm{CeO}_{2}$ modification. Combined with aforementioned results, it implied that improved SCR activity after acid washing and $\mathrm{CeO}_{2}$ adding could be ascribed to optimized acidic sites, which facilitate the low temperature SCR activity and inhibit high temperature $\mathrm{NH}_{3}$ oxidation.

\section{CONCLUSIONS}

In this study, a new SCR catalyst regeneration method has been developed. Some conclusions are listed below. 
Table 2. Quantitative analysis of $\mathrm{NH}_{3}-\mathrm{TPD}$ and $\mathrm{H}_{2}$-TPR over the samples* .

\begin{tabular}{|c|c|c|c|c|c|c|}
\hline \multirow[t]{2}{*}{ Samples } & \multicolumn{2}{|c|}{$\begin{array}{l}\text { Peak temperature } \\
\left({ }^{\circ} \mathrm{C}\right)\end{array}$} & \multicolumn{2}{|c|}{$\begin{array}{l}\mathrm{NH}_{3} \text { desorption } \\
\text { (a.u.) }\end{array}$} & \multirow[t]{2}{*}{$\begin{array}{l}\text { Total } \mathrm{NH}_{3} \text { desorption } \\
\text { (a.u.) }\end{array}$} & \multirow{2}{*}{$\begin{array}{l}\text { Total } \mathrm{H}_{2} \text { consumption } \\
\text { (a.u.) }\end{array}$} \\
\hline & $\mathrm{T}_{\mathrm{I}}$ & $\mathrm{T}_{\text {II }}$ & $\mathrm{S}_{\mathrm{I}}$ & $\mathrm{S}_{\mathrm{II}}$ & & \\
\hline Fresh & 178 & 270 & 1.00 & 1.00 & 1.00 & 1.00 \\
\hline $0.5 \mathrm{~K}$ & 165 & 236 & 1.34 & 0.63 & 0.74 & 0.93 \\
\hline $0.5 \mathrm{~K}-0.5 \mathrm{SA}$ & 183 & 293 & 1.22 & 1.05 & 1.08 & 0.63 \\
\hline $0.5 \mathrm{~K}-10 \mathrm{CeO}_{2}$ & 164 & 227 & 1.11 & 0.40 & 0.51 & 1.38 \\
\hline $0.5 \mathrm{~K}-0.5 \mathrm{SA}-3 \mathrm{CeO}_{2}$ & 205 & 314 & 1.64 & 0.73 & 0.86 & 0.67 \\
\hline $0.5 \mathrm{~K}-0.5 \mathrm{SA}-5 \mathrm{CeO}_{2}$ & 188 & 282 & 2.00 & 0.87 & 1.04 & 0.87 \\
\hline $0.5 \mathrm{~K}-0.5 \mathrm{SA}-10 \mathrm{CeO}_{2}$ & 180 & 267 & 1.92 & 0.81 & 0.98 & 0.76 \\
\hline
\end{tabular}

${ }^{*}$ Normalized by the values of the fresh catalyst.

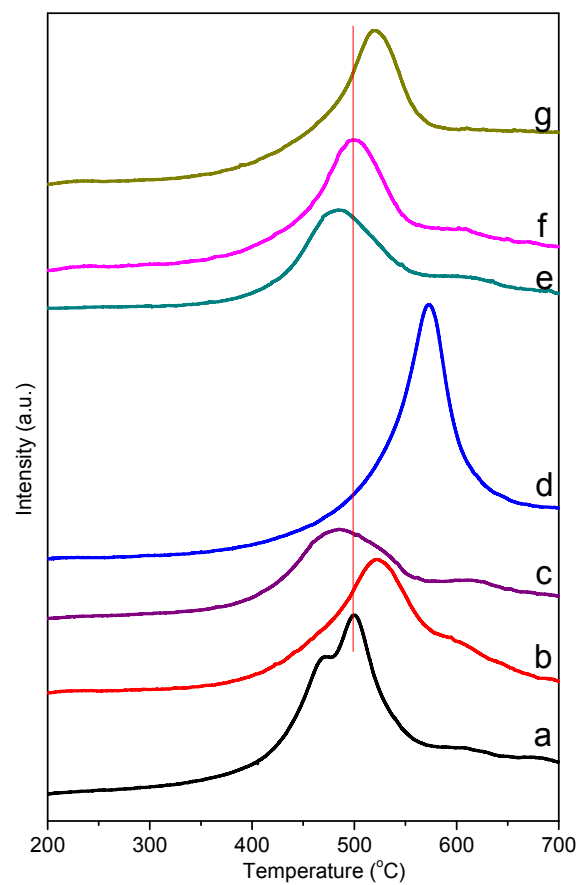

Fig. 8. $\mathrm{H}_{2}$-TPR profiles of the (a) fresh; (b) $0.5 \mathrm{~K}$; (c) $0.5 \mathrm{~K}$ $0.5 \mathrm{SA}$; (d) $0.5 \mathrm{~K}-10 \mathrm{CeO}_{2}$; (e) $0.5 \mathrm{~K}-0.5 \mathrm{SA}-3 \mathrm{CeO}_{2}$; (f) $0.5 \mathrm{~K}-$ $0.5 \mathrm{SA}-5 \mathrm{CeO}_{2} ;(\mathrm{g}) 0.5 \mathrm{~K}-0.5 \mathrm{SA}-10 \mathrm{CeO}_{2}$.

1. Potassium doping had a negative effect on the activity of the catalysts. The increase in the potassium loading amount continuously decreased the NO conversion rate of the catalysts. After washing the catalysts with an $\mathrm{H}_{2} \mathrm{SO}_{4}$ solution and deionized water, the SCR activity was partially restored. The further addition of $\mathrm{CeO}_{2}$ caused the regenerated catalysts to exhibit almost as much activity as the fresh ones.

2. After washing the catalysts with an $\mathrm{H}_{2} \mathrm{SO}_{4}$ solution and deionized water, the potassium species were almost completely removed, benefical to $\mathrm{NH}_{3}$ adsorption. $\mathrm{CeO}_{2}$ was then added to compensate for the lost active species. These factors were primarily responsible for the recovery of the catalyst activity after regeneration.

\section{ACKNOWLEDGMENTS}

This work is supported by the National Key Research and Development Program of China (No. 2018YFC0213400), National Science Foundation of China (No. U1609212 and No. 51306079), and Open Fund of Key Laboratory of Ministry of Education of China (No. LLEUTS-201507).

\section{DISCLAIMER}

Reference to any companies or specific commercial products does not constitute.

\section{SUPPLEMENTARY MATERIAL}

Supplementary data associated with this article can be found in the online version at http://www.aaqr.org.

\section{REFERENCES}

Busca, G., Lietti, L., Ramis, G. and Berti, F. (1998). Chemical and mechanistic aspects of the selective catalytic reduction of $\mathrm{NO}_{\mathrm{x}}$ by ammonia over oxide catalysts: A review. Appl. Catal. B 18: 1-36.

Castellino, F., Jensen, A.D., Johnsson, J.E. and Fehrmann, R. (2009). Influence of reaction products of K-getter fuel additives on commercial vanadia-based SCR catalysts: Part I. Potassium phosphate. Appl. Catal. Environ. 86: 196-205.

Chen, L., Li, J. and Ge, M. (2009). Promotional effect of Ce-Doped $\mathrm{V}_{2} \mathrm{O}_{5}-\mathrm{WO}_{3} / \mathrm{TiO}_{2}$ with low vanadium loadings for selective catalytic reduction of $\mathrm{NO}_{x}$ by $\mathrm{NH}_{3} . J$. Phys. Chem. C 113: 21177-21184.

Chen, L., Li, J.H. and Ge, M.F. (2011). The poisoning effect of alkali metals doping over nano $\mathrm{V}_{2} \mathrm{O}_{5^{-}}$ $\mathrm{WO}_{3} / \mathrm{TiO}_{2}$ catalysts on selective catalytic reduction of $\mathrm{NO}_{x}$ by $\mathrm{NH}_{3}$. Chem. Eng. J. 170: 531-537.

Chen, Y., Wang, M., Du, X., Ran, J., Zhang, L. and Tang, D. (2018). High resistance to $\mathrm{Na}$ poisoning of $\mathrm{V}_{2} \mathrm{O}_{5^{-}}$ $\mathrm{Ce}\left(\mathrm{SO}_{4}\right)_{2} / \mathrm{TiO}_{2}$ catalyst for the $\mathrm{NO} \mathrm{SCR}$ reaction. Aerosol Air Qual. Res. 18: 2948-2955.

Due-Hansen, J., Boghosian, S., Kustov, A., Fristrup, P., Tsilomelekis, G., Stahl, K., Christensen, C.H. and Fehrmann, R. (2007). Vanadia-based SCR catalysts supported on tungstated and sulfated zirconia: Influence of doping with potassium. J. Catal. 251: 459-473.

Du, X., Xue, J., Wang, X., Chen, Y., Ran, J. and Zhang, L. (2018). Oxidation of sulfur dioxide over $\mathrm{V}_{2} \mathrm{O}_{5} / \mathrm{TiO}_{2}$ 
catalyst with low vanadium loading: A theoretical study. J. Phys. Chem. C 122: 4517-4523.

Forzatti, P. (2001). Present status and perspectives in de$\mathrm{NO}_{\mathrm{x}}$ SCR catalysis. Appl. Catal. A 222: 221-236.

Guan, B., Lin, H., Zhu, L. and Huang, Z. (2011). Selective catalytic reduction of $\mathrm{NO}_{x}$ with $\mathrm{NH}_{3}$ over Mn, Ce substitution $\mathrm{Ti}_{0.9} \mathrm{~V}_{0.1} \mathrm{O}_{2-\delta}$ nanocomposites catalysts prepared by self-propagating high-temperature synthesis method. J. Phys. Chem. C 115: 12850-12863.

Hu, W., Zhang, Y., Liu, S., Zheng, C., Gao, X., Nova, I. and Tronconi, E. (2017). Improvement in activity and alkali resistance of a novel $\mathrm{V}-\mathrm{Ce}\left(\mathrm{SO}_{4}\right)_{2} / \mathrm{Ti}$ catalyst for selective catalytic reduction of $\mathrm{NO}$ with $\mathrm{NH}_{3}$. Appl. Catal. B 206: 449-460.

Huang, X., Ma, Z., Lin, W., Liu, F. and Yang, H. (2017). Activation of fast selective catalytic reduction of $\mathrm{NO}$ by $\mathrm{NH}_{3}$ at low temperature over $\mathrm{TiO}_{2}$ modified $\mathrm{CuO}_{\mathrm{x}}-\mathrm{CeO}_{\mathrm{x}}$ composites. Catal. Commun. 91: 53-56.

Jiang, Y., Wang, X., Xing, Z., Bao, C. and Liang, G. (2017). Preparation and characterization of $\mathrm{CeO}_{2}$ $\mathrm{MoO}_{3} / \mathrm{TiO}_{2}$ catalysts for selective catalytic reduction of $\mathrm{NO}$ with $\mathrm{NH}_{3}$. Aerosol Air Qual. Res. 17: 465-469.

Jiang, Y., Bao, C., Liu, S., Liang, G., Lu, M., Lai, C., Shi, W. and Ma, S. (2018). Enhanced activity of Nb-modified $\mathrm{CeO}_{2} / \mathrm{TiO}_{2}$ catalyst for the selective catalytic reduction of NO with $\mathrm{NH}_{3}$. Aerosol Air Qual. Res. 18: 2121-2130.

Kamata, H., Takahashi, K. and Odenbrand, C.U.I. (1999). The role of $\mathrm{K}_{2} \mathrm{O}$ in the selective reduction of $\mathrm{NO}$ with $\mathrm{NH}_{3}$ over a $\mathrm{V}_{2} \mathrm{O}_{5}\left(\mathrm{WO}_{3}\right) / \mathrm{TiO}_{2}$ commercial selective catalytic reduction catalyst. J. Mol. Catal. A 139: 189198.

Khodayari, R. and Odenbrand, C.U.I. (2001a). Regeneration of commercial scr catalysts by washing and sulphation: Effect of sulphate groups on the activity. Appl. Catal. B 33: 277-291.

Khodayari, R. and Odenbrand, C.U.I. (2001b). Regeneration of commercial $\mathrm{TiO}_{2}-\mathrm{V}_{2} \mathrm{O}_{5}-\mathrm{WO}_{3} \mathrm{SCR}$ catalysts used in bio fuel plants. Appl. Catal. B 30: 87-99.

Klimczak, M., Kern, P., Heinzelmann, T., Lucas, M. and Claus, P. (2010). High-throughput study of the effects of inorganic additives and poisons on $\mathrm{NH}_{3}$-SCR catalysts Part I: $\mathrm{V}_{2} \mathrm{O}_{5}-\mathrm{WO}_{3} / \mathrm{TiO}_{2}$ catalysts. Appl. Catal. B 95: 3947.

Kustov, A.L., Kustova, M.Y., Fehrmann, R. and Simonsen, P. (2005). Vanadia on sulphated- $\mathrm{ZrO}_{2}$, a promising catalyst for $\mathrm{NO}$ abatement with ammonia in alkali containing flue gases. Appl. Catal. B 58: 97-104.

Lei, Z.G., Liu, X.Y. and Jia, M.R. (2009). Modeling of selective catalytic reduction (SCR) for NO removal using monolithic honeycomb catalyst. Energy Fuels 23: 6146-6151.

Li, L., Zhang, L., Ma, K., Zou, W., Cao, Y., Xiong, Y., Tang, C. and Dong, L. (2017). Ultra-low loading of copper modified $\mathrm{TiO}_{2} / \mathrm{CeO}_{2}$ catalysts for lowtemperature selective catalytic reduction $\mathrm{Of} \mathrm{NO}$ by $\mathrm{NH}_{3}$. Appl. Catal. B 207: 366-375.

Li, Q., Hou, X., Yang, H., Ma, Z., Zheng, J., Liu, F., Zhang, X. and Yuan, Z. (2012). Promotional effect of $\mathrm{CeO}_{\mathrm{x}}$ for $\mathrm{NO}$ reduction over $\mathrm{V}_{2} \mathrm{O}_{5} / \mathrm{TiO}_{2}$-carbon nanotube composites. J. Mol. Catal. A 356: 121-127.

Lisi, L., Lasorella, G., Malloggi, S. and Russo, G. (2004). Single and combined deactivating effect of alkali metals and $\mathrm{HCl}$ on commercial SCR catalysts. Appl. Catal. B 50: 251-258.

Moradi, F., Brandin, J., Sohrabi, M., Faghihi, M. and Sanati, M. (2003). Deactivation of oxidation and SCR catalysts used in flue gas cleaning by exposure to aerosols of high- and low melting point salts, potassium salts and zinc chloride. Appl. Catal. B 46: 65-76.

Putluru, S.S.R., Riisager, A. and Fehrmann, R. (2009). The effect of acidic and redox properties of $\mathrm{V}_{2} \mathrm{O}_{5} / \mathrm{CeO}_{2}-\mathrm{ZrO}_{2}$ catalysts in selective catalytic reduction of $\mathrm{NO}$ by $\mathrm{NH}_{3}$. Catal. Lett. 133: 370-375.

Shi, Y., Wang, X., Xia, Y., Sun, C., Zhao, C., Li, S. and $\mathrm{Li}, \mathrm{W}$. (2017). Promotional effect of $\mathrm{CeO}_{2}$ on the propene poisoning resistance of HBEA zeolite catalyst for $\mathrm{NH}_{3}-\mathrm{SCR}$ of $\mathrm{NO}_{x}$. Mol. Catal. 433: 265-273.

Tang, F.S., Xu, B.L., Shi, H.H., Qiu, J.H. and Fan, Y.N. (2010). The poisoning effect of $\mathrm{Na}^{+}$and $\mathrm{Ca}^{2+}$ ions doped on the $\mathrm{V}_{2} \mathrm{O}_{5} / \mathrm{TiO}_{2}$ catalysts for selective catalytic reduction of $\mathrm{NO}$ by $\mathrm{NH}_{3}$. Appl. Catal. B 94: 71-76.

Topsoe, N.Y. (1994). Mechanism of the selective catalytic reduction of nitric oxide by ammonia elucidated by in situ on-line fourier transform infrared spectroscopy. Science 265: 1217-1219.

Topsoe, N.Y., Topsoe, H. and Dumesic, J.A. (1995). Vanadia/Titania catalysts for selective catalytic reduction (SCR) of nitric-oxide by ammonia: 1. Combined temperature-programmed in-situ FTIR and online massspectroscopy studies. J. Catal. 151: 226-240.

Wang, X., Du, X., Zhang, L., Yang, G., Chen, Y. and Ran, J. (2018). Simultaneous fast decomposition of $\mathrm{NH}_{4} \mathrm{HSO}_{4}$ and efficient $\mathrm{NO}_{\mathrm{x}}$ removal by $\mathrm{NO}_{2}$ addition: an option for $\mathrm{NO}_{\mathrm{x}}$ removal in $\mathrm{H}_{2} \mathrm{O} / \mathrm{SO}_{2}$-contained flue gas at a low temperature. Energy Fuels 32: 6990-6994.

Wang, X., Du, X., Zhang, L., Chen, Y., Yang, G. and Ran, J. (2018a). Promotion of $\mathrm{NH}_{4} \mathrm{HSO}_{4}$ decomposition in $\mathrm{NO} / \mathrm{NO}_{2}$ contained atmosphere at low temperature over $\mathrm{V}_{2} \mathrm{O}_{5}-\mathrm{WO}_{3} / \mathrm{TiO}_{2}$ catalyst for $\mathrm{NO}$ reduction. Appl. Catal. A 559: 112-121.

Wang, X., Shi, Y., Li, S. and Li, W. (2018b). Promotional synergistic effect of $\mathrm{Cu}$ and $\mathrm{Nb}$ doping on a novel $\mathrm{Cu} / \mathrm{Ti}-\mathrm{Nb}$ ternary oxide catalyst for the selective catalytic reduction of $\mathrm{NO}_{x}$ with $\mathrm{NH}_{3}$. Appl. Catal. B 220: 234 250.

Yao, X., Zhao, R., Chen, L., Du, J., Tao, C., Yang, F. and Dong, L. (2017). Selective catalytic reduction of $\mathrm{NO}_{\mathrm{x}}$ by $\mathrm{NH}_{3}$ over $\mathrm{CeO}_{2}$ supported on $\mathrm{TiO}_{2}$ : Comparison of anatase, brookite, and rutile. Appl. Catal. B 208: 82-93.

Ye, D., Qu, R., Zhang, Y., Wu, W., Liu, S., Zheng, C. and Gao, X. (2018). Investigating the role of $\mathrm{H}_{4} \mathrm{SiW}_{12} \mathrm{O}_{40}$ in the acidity, oxidability and activity of $\mathrm{H}_{4} \mathrm{SiW}_{12} \mathrm{O}_{40^{-}}$ $\mathrm{Fe}_{2} \mathrm{O}_{3}$ catalysts for the selective catalytic reduction of $\mathrm{NO}$ with $\mathrm{NH}_{3}$. Mol. Catal. 448: 177-184.

Zhang, X., Li, X.G., Wu, J.S., Yang, R.C. and Zhang, Z.H. (2009). Selective catalytic reduction of NO by ammonia on $\mathrm{V}_{2} \mathrm{O}_{5} / \mathrm{TiO}_{2}$ catalyst prepared by sol-gel method. Catal. Lett. 130: 235-238. 
Zheng, Y.J., Jensen, A.D. and Johnsson, J.E. (2004). Laboratory investigation of selective catalytic reduction catalysts: Deactivation by potassium compounds and catalyst regeneration. Ind. Eng. Chem. Res. 43: 941-947.

Zheng, Y.J., Jensen, A.D. and Johnsson, J.E. (2005). Deactivation of $\mathrm{V}_{2} \mathrm{O}_{5}-\mathrm{WO}_{3}-\mathrm{TiO}_{2}$ SCR catalyst at a biomass-fired combined heat and power plant. Appl.
Catal. B 60: 253-264.

Received for review, July 24, 2018 Revised, November 12, 2018 Accepted, December 11, 2018 